\title{
Time Value Of Money And Its Applications In Corporate Finance: A Technical Note On Linking Relationships Between Formulas

\author{
Jeng-Hong Chen, Albany State University, USA
}

\begin{abstract}
Time Value of Money (TVM) is the most important chapter in the basic corporate finance course. It is imperative to understand TVM formulas because they imply important TVM concepts. Students who really understand TVM concepts and formulas can learn better in chapters of TVM applications. This technical note intends to present more complete TVM formulas and link their relationships from the growing annuity perspective to assist instructors in teaching and students in learning. Although TVM formulas are already available in the textbooks, this technical note provides another perspective of presenting and summarizing TVM formulas. The simplification or extension of the growing annuity formula to reach other TVM formulas is discussed in this note.
\end{abstract}

Keywords: Time Value of Money Formulas, The Growing Annuity

\section{INTRODUCTION}

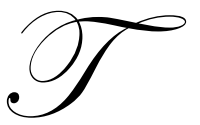

ime Value of Money (TVM) is the most important chapter in the basic corporate finance course in business education. ${ }^{1}$ Students who really understand TVM concepts and formulas can learn better in TVM applications, such as bond valuation, stock valuation, cost of capital, and capital budgeting. Due to the technological advancement, TVM formulas are built in the financial calculator and students can utilize its function keys to work TVM calculations efficiently. Although financial calculators help students compute answers faster, understanding TVM formulas is still imperative because these formulas imply important TVM concepts. With solid understanding of TVM formulas, students are able to identify what the questions ask and compute the correct answers by using either formulas or function keys.

When learning TVM, students may see many formulas listed in the textbook. Some students may think these formulas are difficult to understand because they are confused with these formulas. In fact, most of TVM formulas are closely related. When introducing TVM formulas, the instructor can classify them under different conditions and link their relationships to organize them. This way is easier for students to better understand these formulas and the essence of TVM. Moreover, students can learn better in TVM applications, taught in later chapters.

TVM formulas are available in the textbooks. Some textbooks only list frequently used formulas while others include more formulas. In addition, different textbooks present and organize TVM formulas in different ways. This technical note intends to present more complete TVM formulas and link their relationships from the growing annuity perspective to assist instructors in teaching and students in learning. Although many TVM formulas listed in this technical note can be found in the textbooks, it provides another perspective of presenting and summarizing TVM formulas. The simplification or extension of the growing annuity formula to reach other TVM formulas is discussed in this note.

The remainder of this technical note is organized as follows. Section 2 describes the growing annuity. Section 3 simplifies or extends the growing annuity formula to reach other TVM formulas and links their relationships. Section 4 concludes this note with tables summarizing TVM formulas discussed in section 3. 


\section{THE GROWING ANNUITY}

For the growing annuity, the payment is expected to grow at a constant rate for a finite number of periods. The formulas for the present value (PV) of growing annuity and the future value (FV) of growing annuity are shown as follows and derived in Appendix A.

$$
\begin{aligned}
& P V_{\text {growing annuity }}=\frac{P M T\left(1-\left(\frac{1+g}{1+i}\right)^{n}\right)}{i-g} \\
& F V_{\text {growing annuity }}=\frac{P M T\left((1+i)^{n}-(1+g)^{n}\right)}{i-g}
\end{aligned}
$$

Where

PMT: Payment at end of the first period (Payment one period from today)

$g$ : the payment growth rate per period

$i$ : the interest rate per period ${ }^{2}$

$n$ : number of periods

\section{OTHER TVM FORMULAS}

Other TVM formulas can be achieved by simplifying or extending equation (1) or (2), the formula for the $\mathrm{PV}$ or FV of growing annuity.

\subsection{Present Value Interest Factor Annuity $\left(\operatorname{PVIFA}_{\mathbf{i}, \mathrm{n}}\right)$}

Present value interest factor annuity $\left(\mathrm{PVIFA}_{\mathrm{i}, \mathrm{n}}\right)$ represents the PV of $\$ 1$ payment $(\mathrm{PMT}=\$ 1)$ occurred at end of each period for a finite number of periods. $\mathrm{PVIFA}_{\mathrm{i}, \mathrm{n}}$, which requires PMT $=\$ 1$ and $\mathrm{g}=0$ (zero growth rate because of the same amount of PMT each period), is a special case of PV of growing annuity. When PMT $=\$ 1$ and $\mathrm{g}=0$, equation (1) will be simplified to the following equation (3).

PVIFA $_{i, n}=\frac{\left(1-\frac{1}{(1+i)^{n}}\right)}{i}$

Many finance and accounting textbooks put PVIFA $\mathrm{i}_{\mathrm{i}, \mathrm{n}}$ table in the appendix. The numbers in table are made based on equation (3).

\subsubsection{Present Value (PV) of Ordinary Annuity}

PV of ordinary annuity means the PV of same PMT (PMT > \$0) occurred at end of each period for a finite number of periods. PV of ordinary annuity, which requires $\mathrm{g}=0$ (zero growth rate because of the same amount of PMT each period), is a special case of PV of growing annuity. To get PV of ordinary annuity, we can either simplify equation (1) by assuming $\mathrm{g}=0$ or use PMT to multiply by equation (3). as follow.

So, let $\mathrm{g}=0$ in equation (1) or use PMT to multiply by equation (3). PV of ordinary annuity can be reached 


$$
P V_{\text {ordinary annuity }}=\frac{P M T\left(1-\frac{1}{(1+i)^{n}}\right)}{i}=P M T \times P V I F A_{i, n}
$$

\subsubsection{Present Value (PV) of Annuity Due}

Comparing annuity due with ordinary annuity, we can find the following relationship.

$$
P V_{\text {annuity due }}=P V_{\text {ordinary annuity }} \times(1+i)
$$

The detailed proof of equation (5) is shown in Appendix B.

Use equation (3) to multiply by (1+i). We get

$$
\begin{aligned}
& \operatorname{PVIFA}_{i, n} \times(1+i) \\
& =\frac{\left(1-\frac{1}{(1+i)^{n}}\right)}{i} \times(1+i)=\frac{\left((1+i)-\frac{1}{(1+i)^{n-1}}\right)}{i}=\frac{\left(1-\frac{1}{(1+i)^{n-1}}\right)}{i}+1=P_{V I F A_{i, n-1}}+1
\end{aligned}
$$

Combine equation (4), (5), and (6). PV of annuity due can be written as follow.

$$
P V_{\text {annuity due }}=P M T \times P V I F A_{i, n} \times(1+i)=P M T \times\left(P V I F A_{i, n-1}+1\right)
$$

\subsection{Future Value Interest Factor Annuity $\left(\right.$ FVIFA $\left._{i, n}\right)$}

Future value interest factor annuity $\left(\mathrm{FVIFA}_{\mathrm{i}, \mathrm{n}}\right)$ represents the future value $(\mathrm{FV})$ of $\$ 1$ payment $(\mathrm{PMT}=\$ 1)$ occurred at end of each period for a finite number of periods. $\mathrm{FVIFA}_{\mathrm{i}, \mathrm{n}}$, which requires PMT $=\$ 1$ and $\mathrm{g}=0$ (zero growth rate because of the same amount of PMT each period), is a special case of FV of growing annuity. When $\mathrm{PMT}=\$ 1$ and $\mathrm{g}=0$, equation (2) will be simplified to the following equation (8). ${ }^{3}$

$$
F \operatorname{VIFA}_{i, n}=\frac{\left((1+i)^{n}-1\right)}{i}
$$

Many finance and accounting textbooks also put $\mathrm{FVIFA}_{\mathrm{i}, \mathrm{n}}$ table in the appendix. The numbers in table are made based on equation (8).

\subsubsection{Future Value (FV) of Ordinary Annuity}

FV of ordinary annuity means the FV of same PMT (PMT > \$0) occurred at end of each period for a finite number of periods. FV of ordinary annuity, which requires $\mathrm{g}=0$ (zero growth rate because of the same amount of PMT each period), is a special case of FV of growing annuity. To get FV of ordinary annuity, we can either simplify equation (2) by assuming $\mathrm{g}=0$ or use PMT to multiply by equation (8). as follow.

So, let $\mathrm{g}=0$ in equation (2) or use PMT to multiply by equation (8). FV of ordinary annuity can be reached 


$$
F V_{\text {ordinary annuity }}=\frac{P M T\left((1+i)^{n}-1\right)}{i}=P M T \times F V I F A_{i, n}
$$

\subsubsection{Future Value (FV) of Annuity Due}

Comparing annuity due with ordinary annuity, we can find the following relationship.

$$
F V_{\text {annuity due }}=F V_{\text {ordinary annuity }} \times(1+i)
$$

The detailed proof of equation (10) is also shown in Appendix B.

Use equation (8) to multiply by (1+i). We get

$$
\begin{aligned}
& F_{V I F A_{i, n}} \times(1+i) \\
& =\frac{\left((1+i)^{n}-1\right)}{i} \times(1+i)=\frac{\left((1+i)^{n+1}-(1+i)\right)}{i}=\frac{\left((1+i)^{n+1}-1\right)}{i}-1=F V I F A_{i, n+1}-1
\end{aligned}
$$

Combine equation (9), (10), and (11). FV of annuity due can be written as follow.

$$
F V_{\text {annuity due }}=P M T \times F V I F A_{i, n} \times(1+i)=P M T \times\left(F V I F A_{i, n+1}-1\right)
$$

\subsection{Perpetuity and Stock Valuation (Zero Growth Common Stock and Preferred Stock)}

\subsubsection{Perpetuity}

Perpetuity defines that the same amount of PMT per period occurs forever. Therefore, PMT is the same for each period ( $g=0$, zero growth rate) and the number of periods is infinite $(n \rightarrow \infty)$. Again, based on equation (1), when $\mathrm{g}=0$ and $\mathrm{n} \rightarrow \infty,\left(\frac{1+g}{1+i}\right)^{n}=\frac{1}{(1+i)^{n}} \rightarrow 0 .{ }^{4}$ So, the present value of perpetuity will become

$$
P V_{\text {perpetuity }}=\frac{P M T}{i}
$$

\subsubsection{Stock Valuation: Common Stock (Zero Growth Model)}

Zero growth common stock assumes that the expected future dividend per period will be the same and it will last forever. Actually, this is the same situation as what we discussed for perpetuity. The formula to calculate the value of stock today $\left(\mathrm{P}_{0}\right)$ should be the same as equation (13) except using different notations.

$$
P_{0}=\frac{D}{k_{s}}
$$

In equation (14), D, the expected future dividend per share per period, is like PMT in equation (13) and $\mathrm{k}_{\mathrm{s}}$, the required rate of return on common stock per period, is like i in equation (13). 


\subsubsection{Stock Valuation: Preferred Stock}

Preferred stock has the same situation as perpetuity and zero growth common stock. The fixed amount of dividend is expected to last forever. Again, the formula to calculate the value of preferred stock today $\left(\mathrm{V}_{\mathrm{p}}\right)$ should be the same as equation (13) and (14) except using different notations.

$$
V_{p}=\frac{D_{p}}{k_{p}}
$$

In equation (15), $\mathrm{D}_{\mathrm{p}}$, the fixed amount of preferred stock dividend per share per period, is like PMT in equation (13) and $\mathrm{D}$ in equation (14). $\mathrm{k}_{\mathrm{p}}$, the required rate of return on preferred stock per period, is like $\mathrm{i}$ in equation (13) and $\mathrm{k}_{\mathrm{s}}$ in equation (14). ${ }^{5}$

\subsection{Stock Valuation: Common Stock (Constant Growth Model)}

The constant growth model assumes that the stock dividend per period is expected to grow at the constant rate $(\mathrm{g})$ forever $(\mathrm{n} \rightarrow \infty)$ and the required rate of return should be greater than the dividend growth rate $\left(\mathrm{k}_{\mathrm{s}}>\mathrm{g}\right)$. The constant growth model is like the growing perpetuity.

Again, based on equation (1) and use $\mathrm{D}_{1}\left(=\mathrm{D}_{0}(1+\mathrm{g})\right)$ and $\mathrm{k}_{\mathrm{s}}$ to substitute for PMT and $\mathrm{i}$, respectively.

When $\mathrm{k}_{\mathrm{s}}>\mathrm{g}$ and $\mathrm{n} \rightarrow \infty,\left(\frac{1+g}{1+k_{s}}\right)^{n} \rightarrow 0$. The value of stock today $\left(\mathrm{P}_{0}\right)$ will be as follow.

$$
P_{0}=\frac{D_{1}}{k_{s}-g}=\frac{D_{0}(1+g)}{k_{s}-g}
$$

Where

$D_{0}$ : Today's (just paid) dividend

$D_{1}$ : Dividend at the end of period 1 (Dividend one period from today) ${ }^{6}$ today, $\mathrm{P}_{\mathrm{t}}$.

Equation (16) can be extended to the following equation (17) to calculate the value of stock t periods from

$$
P_{t}=\frac{D_{t+1}}{k_{s}-g}=\frac{D_{0}(1+g)^{t+1}}{k_{s}-g}=\frac{D_{0}(1+g)}{k_{s}-g} \times(1+g)^{t}=P_{0}(1+g)^{t}
$$

\subsection{Two-Stage Growth Stock Valuation}

Some firms have supernormal growth rate for the first few years due to rapid expansion and later go back to the normal growth rate, which continues forever. This is the case of two-stage growth stock. For two-stage growth stock, the dividend growth rate is $\mathrm{g}_{1}$ for the first stage (finite number of $\mathrm{t}$ periods). The dividend growth rate for the second stage is constant at $g_{2}$ from period $t+1$ until infinity. The situation in the first stage is like the growing annuity so equation (1) can be used in the first stage to compute the PV. The constant growth model can be applied to the second stage. $P_{t}$, the value of stock t periods from today, is $D_{t+1} /\left(k_{s}-g_{2}\right)$ based on equation (17). $D_{t+1}$, the dividend per share at period $t+1$, should be $\mathrm{D}_{0}\left(1+\mathrm{g}_{1}\right)^{t}\left(1+\mathrm{g}_{2}\right)$ in this two-stage growth case. To find the $\mathrm{PV}$ of $\mathrm{P}_{t}$, we need to discount $\mathrm{P}_{\mathrm{t}}$ back $\mathrm{t}$ periods. The formula for the value of two-stage growth stock today $\left(\mathrm{P}_{0}\right)$ can be written as follow. 


$$
\begin{aligned}
P_{0}=\frac{D_{1}\left(1-\left(\frac{1+g_{1}}{1+k_{s}}\right)^{t}\right)}{k_{s}-g_{1}}+\frac{P_{t}}{\left(1+k_{s}\right)^{t}} \\
=\frac{D_{1}\left(1-\left(\frac{1+g_{1}}{1+k_{s}}\right)^{t}\right)}{k_{s}-g_{1}}+\frac{D_{t+1}}{\left(1+k_{s}\right)^{t}} \\
=\frac{D_{0}\left(1+g_{1}\right)\left(1-\left(\frac{1+g_{1}}{1+k_{s}}\right)^{t}\right)}{k_{s}-g_{1}}+\frac{D_{0}\left(1+g_{1}\right)^{t}\left(1+g_{2}\right)}{k_{s}-g_{2}}
\end{aligned}
$$

In equation (18), $\mathrm{g}_{1}$ can be greater than $\mathrm{k}_{\mathrm{s}}$ but $\mathrm{g}_{2}$ must be less than $\mathrm{k}_{\mathrm{s}}$. This means the supernormal growth rate of the first stage can be greater than the required rate of return but the normal growth rate of the second stage must be less than the required rate of return.

\subsection{Bond Valuation}

The value of bond is the sum of present value of future coupon payments at end of each period and the present value of face value (par value) at maturity. The yield (yield to maturity) represents the annual rate of return an investor can earn if he or she holds the bond until maturity. The annual coupon bond makes the coupon payment at end of each year and the face value (par value) payment at maturity. The value of annual coupon bond $\left(\mathrm{V}_{\mathrm{B}}\right)$ is calculated as follow. ${ }^{7}$

$$
\begin{aligned}
& V_{B}=\sum_{t=1}^{N} \frac{P M T}{(1+y)^{t}}+\frac{F}{(1+y)^{N}}=P M T \times\left(P V I F A_{y, N}\right)+\frac{F}{(1+y)^{N}} \\
& =\frac{P M T\left(1-\frac{1}{(1+y)^{N}}\right)}{y}+\frac{F}{(1+y)^{N}}
\end{aligned}
$$

Where

$$
\begin{aligned}
& N=\text { Number of years } \\
& P M T=\text { Annual coupon payment (= annual coupon rate } \times \text { face value) } \\
& y=\text { Bond's yield (or called yield to maturity) } \\
& F=\text { Bond's face value (par value), which is generally assumed } \$ 1,000
\end{aligned}
$$

The present value of future coupon payments at end of each year is like the present value of ordinary annuity so equation (4) can be used in this part. The present value of face value (par value) at maturity is like the present value of a lump sum, which is rearranged from equation (C1).

\subsubsection{Internal Rate of Return (IRR)}

Again, bond valuation formula can be written as follow. 


$$
\begin{aligned}
& V_{B}=\sum_{t=1}^{N} \frac{P M T}{(1+y)^{t}}+\frac{F}{(1+y)^{N}} \\
& =\frac{P M T}{1+y}+\frac{P M T}{(1+y)^{2}}+\frac{P M T}{(1+y)^{3}}+\ldots+\frac{P M T}{(1+y)^{N-1}}+\frac{(P M T+F)}{(1+y)^{N}}
\end{aligned}
$$

Rearrange equation (20) by moving $\mathrm{V}_{\mathrm{B}}$ to the right of "=" to get

$$
0=-V_{B}+\frac{P M T}{1+y}+\frac{P M T}{(1+y)^{2}}+\frac{P M T}{(1+y)^{3}}+\ldots+\frac{P M T}{(1+y)^{N-1}}+\frac{(P M T+F)}{(1+y)^{N}}
$$

The internal rate of return (IRR) method, often used in the capital budgeting, defines that IRR is the discount rate, which makes the net present value (NPV) equal to zero. Based on its definition, IRR can be expressed as follow.

$$
0=C F_{0}+\frac{C F_{1}}{1+I R R}+\frac{C F_{2}}{(1+I R R)^{2}}+\frac{C F_{3}}{(1+I R R)^{3}}+\ldots+\frac{C F_{N-1}}{(1+I R R)^{N-1}}+\frac{C F_{N}}{(1+I R R)^{N}}
$$

Comparing equation (21) and (22), we see that the initial investment $\left(\mathrm{CF}_{0}\right.$, negative (cash outflow)) is like the value of bond that investors pay for today $\left(-\mathrm{V}_{\mathrm{B}}\right)$ and IRR is like the yield $(\mathrm{y})$ in bond valuation. It is tedious and time consuming to find y manually since we need to use trial and error method. We usually use the financial calculator's function keys to find $y$. In addition to using $I / Y$ key to find $y$, we can use IRR key to find y because the yield is like the internal rate of return.

\section{CONCLUSION}

From the discussion in the previous section, we can know that TVM formulas are closely related. Based on

\begin{tabular}{|c|c|c|}
\hline Under the Condition of & PV of Growing Annuity [eq (1)] becomes & Extension \\
\hline $\begin{array}{l}\text { PMT }=\$ 1, g=0 \text {, and } \mathrm{n} \text { is } \\
\text { finite }\end{array}$ & - $\quad$ PVIFA $_{\mathrm{i}, \mathrm{n}}[\mathrm{eq}(3)]$ & $\begin{array}{ll} & \text { PVIFA }_{\mathrm{i}, \mathrm{n}} \times(1+\mathrm{i})=\mathrm{PVIFA}_{\mathrm{i}, \mathrm{n}-1}+1 \\
& {[\mathrm{eq}(6)]}\end{array}$ \\
\hline $\begin{array}{l}\mathrm{PMT}>\$ 0(\mathrm{PMT} \neq \$ 1), \mathrm{g}= \\
0, \text { and } \mathrm{n} \text { is finite }\end{array}$ & - $\quad$ PV of Ordinary Annuity [eq (4)] & $\begin{array}{l}\text { - } \quad \text { PV of Ordinary Annuity } \times(1+\mathrm{i})= \\
\text { PV of Annuity Due [eq }(5)] \\
\text { PV of Annuity Due = PMT } \times \\
\text { PVIFA }_{\mathrm{i}, \mathrm{n}} \times(1+\mathrm{i})=\text { PMT } \times \\
\left(\mathrm{PVIFA}_{\mathrm{i}, \mathrm{n}-1}+1\right)[\mathrm{eq}(7)]\end{array}$ \\
\hline $\begin{array}{l}\text { PMT }>\$ 0, \mathrm{~g}=0, \text { and } \mathrm{n} \text { is } \\
\text { infinite }(\mathrm{n} \rightarrow \infty)\end{array}$ & $\begin{array}{ll}- & \text { PV of Perpetuity [eq (13)] } \\
\text { - } & \text { Zero Growth Model [eq (14)] } \\
\text { - } & \text { Value of Preferred Stock [eq (15)] }\end{array}$ & \\
\hline $\begin{array}{l}\text { PMT }>\$ 0 \text {, and } \mathrm{n} \text { is infinite } \\
(\mathrm{n} \rightarrow \infty)\end{array}$ & - $\quad$ Constant Growth Model [eq (16)] & $\begin{array}{ll}\text { - } & \mathrm{P}_{\mathrm{t}}=\mathrm{D}_{\mathrm{t}+1} /\left(\mathrm{k}_{\mathrm{s}}-\mathrm{g}\right)=\mathrm{P}_{0}(1+\mathrm{g})^{\mathrm{t}} \quad[\mathrm{eq} \\
(17)]\end{array}$ \\
\hline
\end{tabular}
different conditions, we can simplify or extend the formula of growing annuity to reach other formulas. The following tables summarize TVM formulas and link their relationships discussed in the previous section.

Table 1: Summary of PV Formulas

The equation number for each formula, eq (\#), is shown in the bracket [ ]. 
Table 2: Summary of FV Formulas

\begin{tabular}{|c|c|c|}
\hline Under the Condition of & FV of Growing Annuity [eq (2)] becomes & Extension \\
\hline $\begin{array}{l}\text { PMT }=\$ 1, \mathrm{~g}=0 \text {, and } \mathrm{n} \text { is } \\
\text { finite }\end{array}$ & - $\quad$ FVIFA $_{\mathrm{i}, \mathrm{n}}[\mathrm{eq}(8)]$ & $\begin{array}{ll}- & \text { FVIFA }_{\mathrm{i}, \mathrm{n}} \times(1+\mathrm{i})=\mathrm{FVIFA}_{\mathrm{i}, \mathrm{n}+1}-1 \\
& {[\mathrm{eq}(11)]}\end{array}$ \\
\hline $\begin{array}{l}\mathrm{PMT}>\$ 0(\mathrm{PMT} \neq \$ 1), \mathrm{g}= \\
0, \text { and } \mathrm{n} \text { is finite }\end{array}$ & - $\quad$ FV of Ordinary Annuity [eq (9)] & $\begin{array}{ll}- & \text { FV of Ordinary Annuity } \times(1+\mathrm{i}) \\
=\mathrm{FV} \text { of Annuity Due [eq }(10)] \\
\text { - } \\
\mathrm{FV} \text { of Annuity Due }=\text { PMT } \times \\
\text { FVIFA }_{\mathrm{i}, \mathrm{n}} \times(1+\mathrm{i})=\mathrm{PMT} \times \\
\left(\mathrm{FVIFA}_{\mathrm{i}, \mathrm{n}+1}-1\right)[\mathrm{eq}(12)]\end{array}$ \\
\hline
\end{tabular}

The equation number for each formula, eq (\#), is shown in the bracket [ ].

Table 3: Two-Stage Growth Stock Valuation and Bond Valuation

\begin{tabular}{|l|l|}
\hline Combination & Valuation \\
\hline $\begin{array}{l}1^{\text {st }} \text { Stage: PV of Growing Annuity } \\
2^{\text {nd }} \text { Stage: Constant Growth Model (Extension) }\end{array}$ & Two-Stage Growth Stock Valuation [eq (18)] \\
\hline $\begin{array}{l}1^{\text {st }} \text { Part: PV of Ordinary Annuity } \\
2^{\text {nd }} \text { Part: PV of a Lump Sum }\end{array}$ & $\begin{array}{l}\text { Bond Valuation [eq (19)] } \\
\text { (Implication: Yield is the IRR.) [eq (20), (21), (22)] }\end{array}$ \\
\hline
\end{tabular}

The equation number for each formula, eq (\#), is shown in the bracket [ ].

\section{AUTHOR INFORMATION}

Jeng-Hong Chen is a faculty member at College of Business, Albany State University. He has experience of teaching corporate finance, business statistics, and principles of microeconomics. His recent research interests include fixed income securities and international finance.

\section{REFERENCES}

1. Brigham, Eugene F. and Joel F. Houston, Fundamentals of Financial Management, Concise $5^{\text {th }}$ Edition, Thomson South-Western, Mason, Ohio, 2006.

2. Ross, Stephen A., Randolph W. Westerfield, and Bradford D. Jordan, Fundamentals of Corporate Finance, $8^{\text {th }}$, McGraw-Hill/Irwin, New York, New York, 2008.

\section{Appendix A: Derivation of the Present Value (PV) of Growing Annuity and the Future Value (FV) of Growing Annuity}

A simple way learned in high school mathematics to derive a geometric series can be as follows.

Suppose a geometric sequence is $a, a r, a r^{2}, a r^{3}, \ldots, a r^{n-1}$ ( $n$ terms and $r$ as common ratio).

Let $S$ be a geometric series, which is the sum of terms of a geometric sequence.

$$
\begin{aligned}
& S=a+a r+a r^{2}+a r^{3}+\ldots+a r^{n-1} \\
& r S=a r+a r^{2}+a r^{3}+\ldots+a r^{n-1}+a r^{n}
\end{aligned}
$$

$(\mathrm{A} 1)-(\mathrm{A} 2)$ [Subtract equation (A2) from equation (A1)], then gives

$$
(1-r) S=a\left(1-r^{n}\right)
$$

Therefore, $S=\frac{a\left(1-r^{n}\right)}{1-r}$ 
For the growing annuity, the payment (PMT), occurred at the end of each period, is expected to grow at the constant rate $(\mathrm{g}$ ) for a finite number of periods ( $\mathrm{n}$ is finite). $\mathrm{i}$ is the interest rate per period. Therefore, the PV of growing annuity is calculated as follow.

$$
P V_{\text {growing annuity }}=\frac{P M T}{1+i}+\frac{P M T(1+g)}{(1+i)^{2}}+\frac{P M T(1+g)^{2}}{(1+i)^{3}}+\ldots+\frac{P M T(1+g)^{n-1}}{(1+i)^{n}}
$$

Since $P V_{\text {growing annuity }}$ is a geometric series, we can apply it to equation (A3).

Substitute $S=P V_{\text {growing annuity }}, a=\frac{P M T}{1+i}$, and $r=\frac{1+g}{1+i}$ in equation (A3). Then, equation (1) is derived as follow.

$$
P V_{\text {growing annuity }}=\frac{\frac{P M T}{1+i} \times\left(1-\left(\frac{1+g}{1+i}\right)^{n}\right)}{1-\frac{1+g}{1+i}}=\frac{\frac{P M T}{1+i} \times\left(1-\left(\frac{1+g}{1+i}\right)^{n}\right)}{\frac{i-g}{1+i}}=\frac{P M T\left(1-\left(\frac{1+g}{1+i}\right)^{n}\right)}{i-g}
$$

The FV of growing annuity is calculated as follow.

$$
F V_{\text {growing annuity }}=P M T(1+i)^{n-1}+P M T(1+g)(1+i)^{n-2}+P M T(1+g)^{2}(1+i)^{n-3}+\ldots+P M T(1+g)^{n-1}
$$

Since $F V_{\text {growing annuity }}$ is a geometric series as well, we can apply it to equation (A3).

Substitute $S=F V_{\text {growing annuity }}, a=P M T(1+i)^{n-1}$, and $r=\frac{1+g}{1+i}$ in equation (A3). Then, equation (2) is derived as follow.

$$
\begin{aligned}
& F V_{\text {growing annuity }}=\frac{P M T(1+i)^{n-1}\left(1-\left(\frac{1+g}{1+i}\right)^{n}\right)}{1-\frac{1+g}{1+i}}=\frac{P M T(1+i)^{n-1}\left(1-\left(\frac{1+g}{1+i}\right)^{n}\right)}{\frac{i-g}{1+i}} \\
& =\frac{P M T(1+i)^{n}\left(1-\left(\frac{1+g}{1+i}\right)^{n}\right)}{i-g}=\frac{P M T\left((1+i)^{n}-(1+g)^{n}\right)}{i-g}
\end{aligned}
$$

\section{Appendix B: Relationships between Ordinary Annuity and Annuity Due}

Ordinary annuity represents the same amount of payment (PMT) at end of each period for a finite number of periods (n). The time line of ordinary annuity is as follow. 


$\begin{array}{lcccccc}0 & 1 & 2 & 3 & & \\ \mid-1 & \text { PMT } & \text { PMT } & \text { PMT } & \ldots & \text { PMT } & \text { PMT }\end{array}$

Based on the above time line, PV of ordinary annuity and FV of ordinary annuity can be expressed as follows.

$$
\begin{aligned}
& P V_{\text {ordinary annuity }}=\frac{P M T}{1+i}+\frac{P M T}{(1+i)^{2}}+\frac{P M T}{(1+i)^{3}}+\ldots+\frac{P M T}{(1+i)^{n-1}}+\frac{P M T}{(1+i)^{n}} \\
& F V_{\text {ordinary annuity }}=P M T(1+i)^{n-1}+P M T(1+i)^{n-2}+P M T(1+i)^{n-3}+\ldots+P M T(1+i)+P M T
\end{aligned}
$$

Annuity due represents the same amount of payment (PMT) at beginning of each period for a finite number of periods (n). The time line of annuity due is as follow.

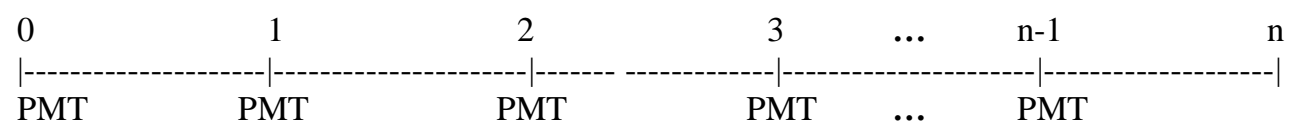

Based on the above time line, PV of annuity due and FV of annuity due can be expressed as follows.

$$
\begin{aligned}
& P V_{\text {annuity due }}=P M T+\frac{P M T}{1+i}+\frac{P M T}{(1+i)^{2}}+\frac{P M T}{(1+i)^{3}}+\ldots+\frac{P M T}{(1+i)^{n-1}} \\
& F V_{\text {annuitydue }}=P M T(1+i)^{n}+P M T(1+i)^{n-1}+P M T(1+i)^{n-2}+P M T(1+i)^{n-3}+\ldots+P M T(1+i)
\end{aligned}
$$

Comparing equation (B1) with (B3), we can find that if (B1) $\times(1+\mathrm{i})$, it will be (B3).

$P V_{\text {annuity due }}=P V_{\text {ordinary annuity }} \times(1+i) \quad$ Thus, equation (5) is proved.

Comparing equation (B2) with (B4), we can find that if (B2) $\times(1+\mathrm{i})$, it will be (B4).

$$
F V_{\text {annuity due }}=F V_{\text {ordinary annuity }} \times(1+i) \quad \text { Thus, equation (10) is proved. }
$$

\section{Appendix C: Find FVIFA $A_{i, n}$ by Compounding PVIFA $A_{i, n}$ for $\mathbf{n}$ Periods}

The most basic TVM formula is

$$
F V=P V(1+i)^{n}
$$

To find $\mathrm{FVIFA}_{\mathrm{i}, \mathrm{n}}$, we can utilize equation (C1) to compound $\mathrm{PVIFA}_{\mathrm{i}, \mathrm{n}}$ for $\mathrm{n}$ periods. Substitute $\mathrm{PVIFA}_{\mathrm{i}, \mathrm{n}}$ (equation (3)) for PV and plug in equation (C1). Therefore, 
VVIFA $_{i, n}=\frac{\left(1-\frac{1}{(1+i)^{n}}\right)}{i} \times(1+i)^{n}=\frac{\left((1+i)^{n}-\frac{(1+i)^{n}}{(1+i)^{n}}\right)}{i}=\frac{\left((1+i)^{n}-1\right)}{i}$

\section{ENDNOTES}

1 To emphasize the importance of TVM, Brigham and Houston (2006) move TVM from Chapter 6 to Chapter 2 to allow students longer time to digest TVM materials before learning TVM application chapters and add more sections in the content of TVM chapter to help students better understand TVM. Ross et al. (2008) use two chapters to introduce TVM and add real world examples and end-of-chapter minicase to enhance TVM content.

${ }^{2}$ When PV (FV) of growing annuity is calculated, $i$ is the discount (compound) rate.

3 Another way to find FVIFA $_{i, n}$ is to compound PVIFA $A_{i, n}$ for $n$ periods. See the details in Appendix C.

4 Similarly, equation (13) can be achieved based on equation (4). When $\mathrm{n} \rightarrow \infty, \frac{1}{(1+i)^{n}} \rightarrow 0$. Then, equation (4) will become equation (13).

5 Equation (15) can be rearranged as $k_{p}=\frac{D_{p}}{V_{p}} . \mathrm{k}_{\mathrm{p}}$ is the required rate of return on preferred stock from the investors' perspective and it is the cost of preferred stock from the firm's perspective. This formula can be used as a component for calculating the firm's weighted average cost of capital if the firm issues the preferred stock.

${ }^{6}$ Equation (16) can be rearranged as $k_{s}=\frac{D_{1}}{P_{0}}+g \cdot \mathrm{k}_{\mathrm{s}}$, which consists of the dividend yield $\left(\mathrm{D}_{1} / \mathrm{P}_{0}\right)$ and the capital gains yield $(\mathrm{g})$, is the required rate of return on common equity from the investors' perspective. $\mathrm{k}_{\mathrm{s}}$ is the cost of common equity from the firm's perspective. This formula can be used as a component for calculating the firm's weighted average cost of capital.

7 Although most bonds are semiannual coupon bonds, for simplicity the annual coupon bond is used for demonstration. We can modify equation (19) by replacing $\mathrm{N}$ with $2 \mathrm{~N}$, replacing PMT with PMT/2, and replacing y with y/2 to find the value of semiannual coupon bond.

${ }^{8}$ We can rearrange equation $(\mathrm{C} 1)$ to get $P V=\frac{F V}{(1+i)^{n}}, i=\left(\frac{F V}{P V}\right)^{\frac{1}{n}}-1$, or $n=\frac{\ln \left(\frac{F V}{P V}\right)}{\ln (1+i)}$. 


\section{NOTES}

